\title{
Quantitative histology in giardiasis
}

\author{
S. G. WRIGHT AND A. M. TOMKINS
}

From the Hospital for Tropical Diseases, St. Pancras Way, London NW1 and the Department of Human Nutrition, London School of Hygiene and Tropical Medicine, London WCI

SUMMARY The Weibel graticule was used to assess quantitatively histological changes in proximal jejunal mucosal biopsies from patients with Giardia lamblia infections. Most had malabsorption. A group of patients who had mild abdominal symptoms but no intestinal infection and normal absorption were the controls.

There were significant differences in mean surface area (SA) measurements between patients with giardiasis and severe malabsorption and controls $(\mathrm{P}<0.001)$ and infected patients with normal absorption $(\mathrm{P}<0.05)$. SA measurements correlated significantly with $\mathrm{D}$-xylose excretion results $(r=0.55 ; \mathrm{P}<0.01)$ and daily facal fat output $(\mathrm{r}=-0.61 ; \mathrm{P}<0.001)$. Significant correlations between duration of symptoms and SA measurements $(\mathrm{r}=0.43 ; \mathrm{P}<0.05)$ and $\mathrm{D}$-xylose excretion $(\mathrm{r}=0.43 ; \mathrm{P}<0.05)$ in giardiasis suggest that histological and functional impairment are maximal soon after infection and resolve in time.

Treatment with metronidazole or mepacrine was associated with a significant increase in SA $(\mathrm{P}<0.05)$ in patients with severe malabsorption but there was little change in SA in a similar group of patients who received tetracycline.

The Weibel graticule was found to be useful in assessing the severity of histological changes and in following changes after treatment.

Quantitation of histological abnormalities is a valuable addition to accurate description of pathological changes in human tissues. It allows correlations with other observations, including clinical and biochemical findings, to be made. The effects of treatment may also be assessed and compared more accurately. Grading systems for human jejunal biopsy specimens based on criteria such as villous height, crypt depth, and lamina propria infiltrate are of value but contain a high degree of subjectivity. Direct measurements of villous height and crypt depth using eyepiece micrometers are useful when excellent orientation can be obtained before fixation. That is frequently not possible with jejunal biopsy specimens as the villi are often distorted when the specimen is extracted from the capsule and orientated on a plane surface for fixation. The Weibel graticule was introduced by Dunnill and Whitehead (1972) for quantitative assessment of human jejunal biopsies. The method has been used in coeliac disease (Dunnill and Whitehead, 1972; Dissanayake et al., 1974; Risdon and Keeling, 1974).

Received for publication 4 January 1978
In the present study the Weibel graticule was used to assess changes in the jejunal mucosa of patients infected with Giardia lamblia. These patients present a wide range of clinical, biochemical, and histological abnormalities (Wright et al., 1977). Malabsorption may be marked but histological changes are less severe than those in coeliac disease.

\section{Patients and methods}

Forty consecutive patients with giardiasis were studied. Full details are published elsewhere (Wright et al., 1977). Ten patients who had mild gastrointestinal symptoms but no parasitic infection and normal intestinal absorption served as controls.

Absorption was assessed by urinary D-xylose excretion after a $\mathbf{2 5} \mathrm{g}$ oral load, daily faecal fat output while on a diet containing $100 \mathrm{~g}$ of fat, and 24hour urinary excretion of 58-Cobalt labelled vitamin $B_{12}$ given with hog intrinsic factor (the Schilling test).

Jejunal biopsies were obtained with a Watson or Quinton capsule positioned under fluoroscopic control in the proximal jejunum. Specimens were orientated on a flat surface and fixed in a modified 
Susa fixative. After paraffin embedding up to 60 serial $5 \mu$ sections were cut, mounted on glass slides, and stained with haematoxylin and eosin. The slides were identified by a number. Where possible biopsies were also obtained after treatment, and they were similarly processed and identified. Sections that were small or poorly orientated were excluded, and 27 biopsies from patients with giardiasis were ultimately assessed. The counting technique has been described elsewhere (Dunnill and Whitehead, 1972; Risdon and Keeling, 1974). The Weibel graticule (Graticules Ltd, Tunbridge Wells, Kent) was positioned in the eyepiece of a Zeiss NF microscope. Total magnification $(12.5 \times 16)$ was kept constant throughout the study. The length (L) of one of the lines seen in the field of view was measured with a stage micrometer $(\mathrm{L}=$ $\left.1.17 \times 10^{-2} \mathrm{~cm}\right)$. For counting, the image of the system of lines on the graticule was positioned as in Fig. 1 with the mid-point of the most inferior line in the field of view over the most superficial fibres of the muscularis mucosae. This was the starting point for examination of each field. The number of points at which the lines cut the microvillous border of the epithelium was counted (SA). This value is a measure of the surface area of the tissue. The number of sites (h) at which either end of any line lay on the tissue section including the epithelium and microvilli was noted. Only villi which were continuous with the rest of the tissue through the villous core and the overlying epithelium were assessed by the technique. Sufficient sections of each specimen were counted for the sum of $h$ to equal or exceed 200 . The reproducibility of the method was assessed by comparing paired counts from two areas in a number of different biopsies.

For each specimen examined the mean values for SA and $h$ were obtained, and the ratio $\left(\frac{S A}{L \times h}\right)$ was calculated. This is a measure of surface area to volume ratio.

\section{Results}

The patients with giardiasis were divided into three groups on the basis of absorption tests. Seven had normal absorption (group M-O), six had a single abnormal absorption test (group M-1), and 14 (group M-2) had impaired absorption of two or three test substances. The results of absorption tests are shown (Fig. 2). Faecal fat estimations were carried out in seven of the 10 control patients.

$$
\text { Correlations of determinations of SA and } \frac{S A}{L \times h}
$$

from two different areas of a series of biopsies were significant $(r=0.95 ; n=7 ; r=0.97 ; n=7$, respectively).

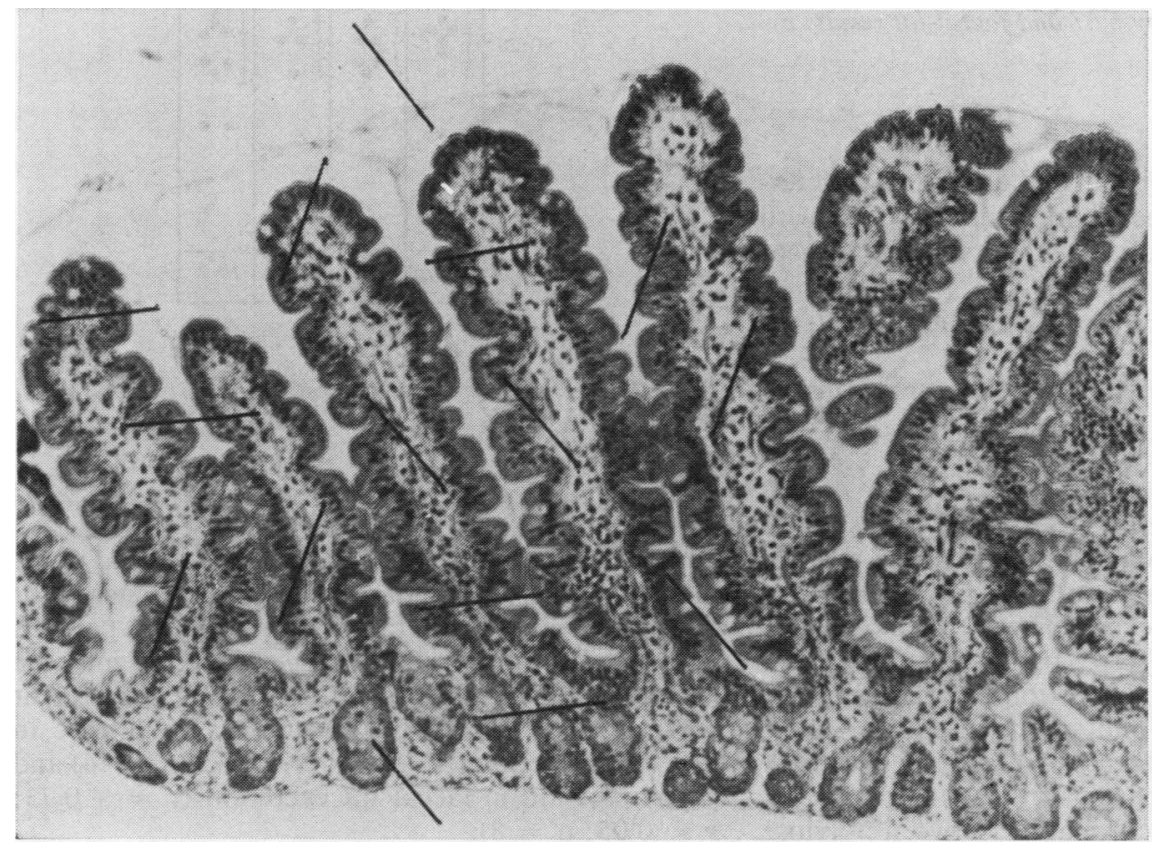

Fig. 1 The graticule in position on a $5 \mu$ section of jejunal mucosa. 


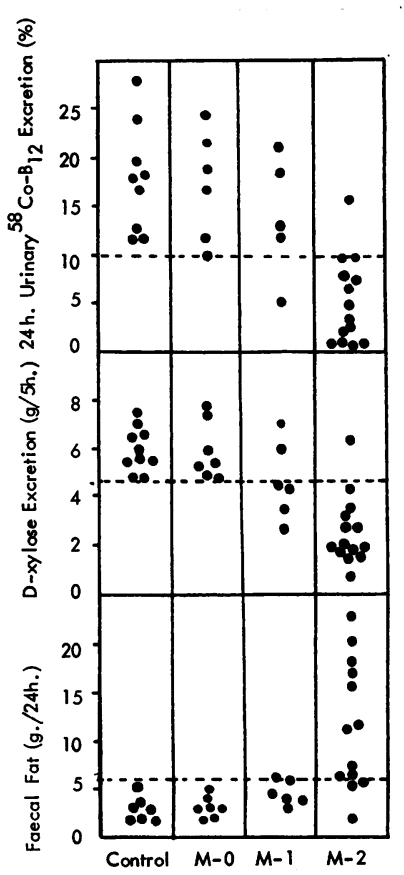

Fig. 2 Results of absorption tests in the four groups. Not shown are one control patient who had a normal whole body vitamin $B_{12}$ absorption test, one group $M-O$ patient whose vitamin $B_{12}$ absorption test was normal, and one group $M-1$ patient whose vitamin $B_{12}$ absorption was abnormal. (Conversion to SI units: multiply D-xylose results by $6 \cdot 67$ and faecal-fat results by 3.0.)

Figures 3 and 4 give results of quantitative determinations in the three groups of patients with giardiasis and the controls. As functional impairment increased, SA and $\frac{\mathrm{SA}}{\mathrm{L} \times \mathrm{h}}$ declined but $(\mathrm{L} \times \mathrm{h})$ remained constant. Table 1 gives comparisons of means for $S A,\left(\frac{S A}{L \times h}\right)$, and $(L \times h)$ for the four groups. Table 2 gives correlations between SA and absorption tests in the patients with giardiasis. Table 3 compares mean SA values of patients with normal and abnormal D-xylose excretion and daily faecal fat output. Those values were significantly lower in patients with abnormal absorption of xylose and fat.

In patients who had had symptoms for up to 52 weeks there was a significant correlation between SA and the duration of symptoms $(r=0.43 ; P<0.05)$. There was a significant correlation between $\mathrm{D}$-xylose

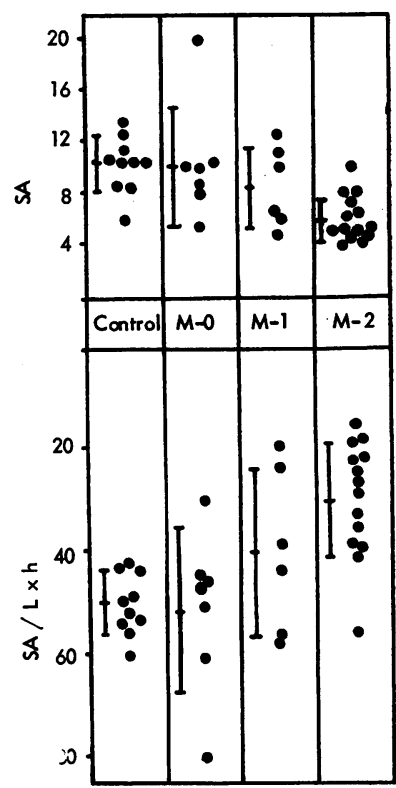

Fig. 3 Results of $S A$ and $\frac{S A}{L \times h}$ are shown. $f$ represents the mean \pm standard deviation.

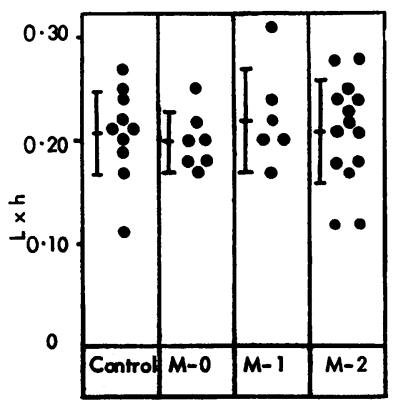

Fig. 4 Results of $L \times h$ for the four groups.

f represents mean \pm standard deviation.

excretion and duration of symptoms ( $r=0.43$; $P<0.05$ ).

After treatment significant changes occurred in SA in eight group M-2 patients who took mepacrine or metronidazole; however, in three group M-2 patients who received tetracycline changes were insignificant (Table 4). Percentage increase in SA after treatment correlated significantly with percentage increase in D-xylose excretion $(r=0.55 ; P<0.05 ; n=14)$ and percentage fall in faecal fat excretion $(r=-0.73$; $\mathrm{P}<0.05 ; \mathrm{n}=8$ ). 
Table 1 Statistical comparisons (Student's t test) between $S A, \frac{S A}{L \times h}$, and $(L \times h)$ for the four groups

\begin{tabular}{|c|c|c|c|c|c|c|}
\hline \multirow[t]{2}{*}{ Comparison of } & \multicolumn{2}{|l|}{$S A$} & \multicolumn{2}{|l|}{$S A$} & \multicolumn{2}{|c|}{$L \times h$} \\
\hline & $\mathbf{t}$ & $\mathbf{P}$ & $\mathbf{t}$ & $\mathbf{P}$ & $\mathbf{t}$ & $\mathbf{P}$ \\
\hline Control and $\mathrm{M}-\mathrm{O}$ & 0.09 & NS & $0 \cdot 28$ & NS & 0.56 & NS \\
\hline Control and $\mathbf{M}-1$ & 1.24 & NS & 1.80 & NS & 0.44 & NS \\
\hline Control and $\mathbf{M}-2$ & $5 \cdot 18$ & $<0.001$ & 5.05 & $<0.001$ & 0 & NS \\
\hline M-O and M-1 & 0.83 & NS & $1 \cdot 31$ & NS & 0.89 & NS \\
\hline$M-O$ and $M-2$ & $2 \cdot 24$ & $<0.05$ & 3.61 & $<0.005$ & 0.49 & NS \\
\hline$M-1$ and $M-2$ & $2 \cdot 37$ & $<0.05$ & $1 \cdot 58$ & NS & 0.41 & NS \\
\hline
\end{tabular}

Table 2 Statistical correlations of results of absorption tests and $S A$ in patients with giardiases

\begin{tabular}{llll}
\hline Correlation of $S A$ and: & $\mathrm{r}$ & $n$ & $\mathrm{P}$ \\
\hline D-xylose excretion $(\mathrm{g} / 5 \mathrm{~h})$ & +0.55 & 25 & $<0.01$ \\
Faecal fat output $(\mathrm{g} / 24 \mathrm{~h})$ & -0.61 & 24 & $<0.001$ \\
Schilling test $(\%$ urinary excretion/24h) & +0.39 & 22 & NS \\
\hline
\end{tabular}

Table 3 Comparison of mean values of SA between patients with giardiasis with normal and abnormal D-xylose, faecal fat, or Schilling test results

\begin{tabular}{lllll}
\hline $\begin{array}{l}\text { Comparison of } S A \text { in } \\
\text { patients with: }\end{array}$ & $S A$ & $S D$ & $n$ & $\begin{array}{l}\text { Statistical } \\
\text { comparison }\end{array}$ \\
\hline $\begin{array}{l}\text { D-xylose } \\
\quad \text { Normal }\end{array}$ & 9.7 & 4.02 & 11 & $\mathrm{t}=2.711$ \\
$\quad \begin{array}{l}\text { Abnormal } \\
\text { Faecal fat }\end{array}$ & 6.4 & 2.41 & 16 & $\mathrm{P}<0.02$ \\
$\quad \begin{array}{l}\text { Normal } \\
\text { Abnormal }\end{array}$ & 9.6 & 3.69 & 15 & $\mathrm{t}=3.615$ \\
$\begin{array}{l}\text { Schilling test } \\
\quad \text { Normal }\end{array}$ & 5.3 & 1.30 & 11 & $\mathrm{P}<0.005$ \\
$\quad$ Abnormal & 8.8 & 4.28 & 11 & $\mathrm{t}=1.564$ \\
\hline
\end{tabular}

Table 4 Results of SA determinations in group $M-2$ patients before and after treatment with the medications shown

\begin{tabular}{llllll}
\hline Treatment & $S A$ & $s$ & $n$ & $\begin{array}{l}\text { Significance } \\
\text { of } \\
\text { difference }\end{array}$ \\
\hline $\begin{array}{l}\text { Metronidazole } \\
2.0 \mathrm{~g} / \text { day } \times 3 \text { days }\end{array}$ & Before & 5.9 & 2.12 & 8 & $\mathrm{t}=2.76$ \\
or & & & & & \\
$\begin{array}{l}\text { Mepacrine } \\
100 \mathrm{mg} \text { tid } \times 10 \text { days }\end{array}$ & After & 9.3 & 2.56 & 8 & $\mathrm{P}<0.05$ \\
& Before & 5.2 & 1.13 & 3 & $\mathrm{NS}$ \\
$\begin{array}{l}\text { Tetracycline } \\
250 \mathrm{mg} \text { qid } \times 28 \text { days }\end{array}$ & After & 5.5 & 1.51 & 3 & \\
\hline
\end{tabular}

\section{Discussion}

Quantitative histology in this study of giardiasis showed a significant decline in SA measurements with the presence of malabsorption. Tissue volume assessed by the product $(L \times h)$ remained constant in the groups studied. This confirms the impression in our previous study (Wright et al., 1977) that increasing functional impairment was associated with more severe histological changes. Normal intestinal function with giardiasis was associated with normal or mildly abnormal histological findings on quantitative histology and subjective grading. Thus a broad spectrum of mucosal changes can be demonstrated using the Weibel graticule technique. These range from gross abnormalities, as in coeliac disease, to the obvious but less gross changes observed in giardiasis with malabsorption reported here.

Statistical correlations cannot be performed using subjective grading systems, and it is in this respect that the method used here is particularly valuable. The numerical results obtained have been correlated with functional measurements and epidemiological data Significant correlations between SA measurements and D-xylose results and faecal fat estimations demonstrate the close association of structure and function in the jejunum, the site of absorption of xylose and fat. Correlations between structure and function have previously been shown only in man using data from intestinal perfusion studies and measurement of villous height and mucosal surface area (Riecken et al., 1976). Mean SA measurements were significantly lower in patients with giardiasis whose absorption of fat or xylose was abnormal while there was no significant difference when mean SA was compared between patients with normal or abnormal absorption of vitamin $B_{12}$. Vitamin $B_{12}$ is normally absorbed in the ileum.

From the significant correlations between SA and D-xylose excretion and duration of symptoms it is apparent that histological and functional abnormalities are maximal early in the course of infection and that these resolve with time. This is in accord with observations on the clinical and parasitological course of the infection in volunteers (Rendtorff, 1954). In eight patients Giardia lamblia was eradicated after treatment with metronidazole or mepacrine, and a significant increase in mean SA was observed. The change in a similar group of patients was insignificant after a course of tetracycline (Wright et al., 1977). Significant correlations between increase in SA and increase in D-xylose excretion and decline in faecal fat output were found after treatment.

The value of quantitative histology using the Weibel graticule has been demonstrated in the investigation of an infectious disease of the small intestine.

We thank Mr R. Preece for technical assistance and Dr G. C. Cook for criticising the manuscript. Dr A. D. M. Bryceson and Dr A. P. Hall kindly allowed us to study patients under their care. 


\section{References}

Dissanayake, A. S., Truelove, S. C., and Whitehead, R. (1974). Jejunal mucosal recovery in coeliac disease in relation to the degree of adherence to a gluten free diet. Quarterly Journal of Medicine, 43, 161-186.

Dunnill, M. S., and Whitehead, R. (1972). A method for the quantitation of small intestinal biopsy specimens. Journal of Clinical Pathology, 25, 243-246.

Rendtorff, R. C. (1954). The experimental transmission of human intestinal protozoan parasites. II. Giardia lamblia cysts given in capsules. American Journal of Hygiene, 59, 209-220.

Riecken, E. O., Lorenz-Meyer, H., Sahfeld, M., and
Bloch, R. (1976). Relationship between structure and function in the human intestine. In Intestinal Ion Transport, edited by J. W. L. Robinson, pp. 371-375. MTP Press, London.

Risdon, R. A., and Keeling, J. W. (1974). Quantitation of the histological changes found in small intestinal biopsy specimens from children with suspected coeliac disease. Gut, 15, 9-18.

Wright, S. G., Tomkins, A. M., and Ridley, D. S. (1977). Giardiasis: clinical and therapeutic aspects. Gut, 18, 343-350.

Requests for reprints to: Dr S. G. Wright, Hospital for Tropical Disease, 4 St. Pancras Way, London NW1 OPE. 